Article

\title{
High CO Methanation Performance of Two-Dimensional Ni/MgAl Layered Double Oxide with Enhanced Oxygen Vacancies via Flash Nanoprecipitation
}

\author{
Mengjuan Zhang ${ }^{1}$, Feng Yu ${ }^{1, *}{ }^{\mathbb{D}}$, Jiangbing Li ${ }^{1}$, Kai Chen ${ }^{1,3}$, Yongbin Yao ${ }^{1}$, Panpan Li ${ }^{1}$, \\ Mingyuan Zhu ${ }^{1}$, Yulin Shi ${ }^{1}$, Qiang Wang ${ }^{1,2, *}$ and Xuhong Guo ${ }^{1,3, *}$ \\ 1 Key Laboratory for Green Processing of Chemical Engineering of Xinjiang Bingtuan, \\ School of Chemistry and Chemical Engineering, Shihezi University, Shihezi 832003, China; \\ mengjuanzhang2017@126.com (M.Z.); ljbin@shzu.edu.cn (J.L.); chenkai@shzu.edu.cn (K.C.); \\ yongbinyao0321@sina.com (Y.Y.); ppl_19910109@163.com (P.L.); zhuminyuan@shzu.edu.cn (M.Z.); \\ shiyulin521@126.com (Y.S.) \\ 2 Environmental Functional Nanomaterials (EFN) Laboratory, College of Environmental Science and \\ Engineering, Beijing Forestry University, Beijing 100083, China \\ 3 State Key Laboratory of Chemical Engineering, East China University of Science and Technology, \\ Shanghai 200237, China \\ * Correspondence: yufeng05@mail.ipc.ac.cn (F.Y.); qiang.wang.ox@gmail.com (Q.W.); \\ guoxuhong@ecust.edu.cn (X.G.); Tel.: +86-993-205-7272 (F.Y. \& Q.W. \& X.G.); \\ Fax: +86-993-205-7270 (F.Y. \& Q.W. \& X.G.)
}

Received: 27 July 2018; Accepted: 27 August 2018; Published: 29 August 2018

\begin{abstract}
As a methanation tool, two-dimensional (2D) carrier-loaded Ni has attracted the attention of many researchers. We successfully prepared 2D MgAl layered double oxides (LDO) carriers via flash nanoprecipitation (FNP). Compared to the LDO samples prepared by conventional co-precipitation (CP), the 2D MgAl-LDO (FNP) has more oxygen vacancies and more exposed active sites. The Ni/MgAl-LDO (FNP) catalyst demonstrates a $\mathrm{CO}$ conversion of $97 \%$, a $\mathrm{CH}_{4}$ selectivity of $79.8 \%$, a turnover frequency of $0.141 \mathrm{~s}^{-1}$, and a $\mathrm{CH}_{4}$ yield of $77.4 \%$ at $350{ }^{\circ} \mathrm{C}$. The weight hourly space velocity was $20,000 \mathrm{~mL} \cdot \mathrm{g}^{-1} \cdot \mathrm{h}^{-1}$ with a synthesis gas flow rate of $65 \mathrm{~mL} \cdot \mathrm{min}^{-1}$, and a pressure of $1 \mathrm{~atm}$. A control experiment used the $\mathrm{CP}$ method to prepare Ni/MgAl-LDO. This material exhibits a CO conversion of $81.1 \%$, a $\mathrm{CH}_{4}$ selectively of $75.1 \%$, a TOF of $0.118 \mathrm{~s}^{-1}$, and a $\mathrm{CH}_{4}$ yield of $61 \%$ at $450{ }^{\circ} \mathrm{C}$. We think that this FNP method can be used for the preparation of more 2D LDO catalysts.
\end{abstract}

Keywords: $\mathrm{CO}$ methanation; oxygen vacancy; layered double oxide; synthesis gas; synthetic natural gas; flash nanoprecipitation

\section{Introduction}

Natural gas (i.e., methane) is a popular clean energy source that provides an important process to remedy air pollution. Coal currently accounts for $66 \%$ of the total energy consumption in China [1-3], which is produced by synthetic natural gas (SNG) by $\mathrm{C} 1$ chemical processes $[4,5]$. Another approach converts $\mathrm{CO}$ waste gas to methane [6-8]. Supported Ni-based catalysts are widely used for CO methanation due to their high catalytic activities and low cost [9]. In recent years, two-dimensional materials have been used to prepare catalyst carriers due to their larger surface area and more active sites. From previous reports, two-dimensional (2D) $\mathrm{SiO}_{2}$ nanomesh was successfully prepared and supported Ni nanoparticles for CO methanation [10,11]. Versus three-dimensional (3D) MCM-41 
molecular sieve catalysts (Ni/3D-MCM-41), the Ni/2D-SiO ${ }_{2}$ catalyst showed remarkable catalytic activity with high $\mathrm{CO}$ conversion and $\mathrm{CH}_{4}$ selectivity at $450{ }^{\circ} \mathrm{C}$.

Natural mineral vermiculite (VMT) with a 2D structure as a catalyst support was reported [12]. Li et al. [13] attempted to expand multilayered vermiculite as a catalyst support and successfully synthesized NiO/VMT composite by microwave irradiation-assisted synthesis (MIAS). The Ni/VMT (MIAS) resulted in highly dispersed active sites and exhibited excellent catalysis performance, including a $99.6 \% \mathrm{CO}$ conversion and $93.8 \% \mathrm{CH}_{4}$ selectivity at $400{ }^{\circ} \mathrm{C}$. Zhang et al. [14] synthesized a $2 \mathrm{D}$ plasma-treated vermiculite (PVMT) with low Ni loading $(0.5 \mathrm{wt} \%)$ via a plasma irradiation method (PIM). The PIM-Ni/PVMT exhibited superior catalytic performance, and the plasma-treated catalyst PIM-Ni/PVMT achieved a CO conversion of $93.5 \%$ and a turnover frequency (TOF) of $0.8537 \mathrm{~s}^{-1}$ at a temperature of $450{ }^{\circ} \mathrm{C}$ and a pressure of $1.5 \mathrm{MPa}$.

Other 2D catalysts for CO methanation include 2D Ni-based layered double oxides (LDO) from layered double hydroxides (LDH). These systems are popular because of their high $\mathrm{Ni}$ dispersibility $[15,16]$. NiAl-LDO offers excellent activity for methanation under $2.0 \mathrm{MPa}$ and $527^{\circ} \mathrm{C}$. NiAl-LDO catalysts with $56.5 \mathrm{wt} \% \mathrm{Ni}$ achieved $97 \%$ CO conversion in a pilot methanation unit. Bian et al. [17] synthesized a NiAl-LDO catalyst that displayed high catalytic stability due to high $\mathrm{Ni}$ dispersion and strong resistance to coke deposition versus the impregnated catalyst. Nearly $100 \% \mathrm{CO}$ conversion was achieved with reaction temperatures between 400 and $500{ }^{\circ} \mathrm{C}$ with a weight hourly space velocity (WHSV) of $300,000 \mathrm{~mL} \cdot \mathrm{g}^{-1} \cdot \mathrm{h}^{-1}$.

$\mathrm{Mg}$ adulteration can also improve the anti-coke ability of Ni-based catalysts. Li et al. [18] synthesized Ni-Mg-Al LDO (i.e., NiMg8, Ni/Mg = 1/8) via a co-precipitation method. The as-obtained catalyst with $11 \mathrm{wt} \% \mathrm{Ni}$ had the best CO methanation performance due to the small size of Ni particles and high Ni dispersion. The NiMg8 had excellent performance: $99.8 \% \mathrm{CO}$ conversion and $73.6 \% \mathrm{CH}_{4}$ selectivity at $550^{\circ} \mathrm{C}$. Li et al. [19] synthesized Ni/VMT-LDO via an impregnation method. The results showed that $\mathrm{Fe}$ and Ca modification improved the dispersion of nickel. Additionally, the small $\mathrm{Ni}$ nanoparticles led to great performance. Furthermore, the Ni/VMT-LDO catalyst offered good low temperature activity with $87.9 \% \mathrm{CO}$ conversion and $90 \% \mathrm{CH}_{4}$ selectivity at $400{ }^{\circ} \mathrm{C}$.

From our previous work [20], the facile flash nanoprecipitation (FNP) method was used to synthesize Mn-Ce-Al mixed metal oxide as SCR catalysts for de-NO $\mathrm{N}_{\mathbf{x}}$. Herein, we successfully synthesized 2D MgAl-LDO support with a high concentration of oxygen vacancies via the facile FNP method. The results showed that $2 \mathrm{D} \mathrm{MgAl}-\mathrm{LDO}$ (FNP) supports exhibited more oxygen vacancies than 2D MgAl-LDO (CP). The 2D MgAl-LDO (FNP)-supported Ni nanoparticles presented abundant active sites for $\mathrm{CO}$ methanation reactions and exhibited excellent catalytic performance. FNP is a simple, novel, and scalable method that can produce nanoparticles with a multi-inlet vortex mixer [21,22]. We think that FNP provides a powerful method to prepare 2D LDOs, which shows considerable potential as a catalyst.

\section{Results and Discussion}

Figure 1a,b show the catalytic performance of the obtained catalysts with a weight hourly space velocity (WHSV) of 20,000 $\mathrm{mLg}^{-1} \mathrm{~h}^{-1}$. Notably, the CO conversion of Ni/MgAl-LDO (CP) catalyst neared zero, whereas that of Ni/MgAl-LDO (FNP) achieved about $18 \%$ at $250{ }^{\circ} \mathrm{C}$. With increasing temperature, for the $\mathrm{Ni} / \mathrm{MgAl}-\mathrm{LDO}$ (FNP) catalyst, $\mathrm{CO}$ conversion sharply rose and achieved a maximum $\mathrm{CO}$ conversion of $97 \%$ and a $\mathrm{CH}_{4}$ selectivity of $79.8 \%$ at $350{ }^{\circ} \mathrm{C}$. However, the $\mathrm{Ni} / \mathrm{MgAl}-\mathrm{LDO}$ (FNP) catalyst reached a maximum $\mathrm{CO}$ conversion of $81.1 \%$ and $\mathrm{CH}_{4}$ selectivity of $75.1 \%$ at $450{ }^{\circ} \mathrm{C}$. Compared with the Ni/MgAl-LDO (CP) catalyst, the Ni/MgAl-LDO (FNP) demonstrated remarkable catalytic activity at low temperature and a broader temperature range for target production.

The turnover frequency (TOF) value of the samples was a key dependent variable for the catalytic performance, as shown in Figure 1c. From the results, the TOF of Ni/MgAl-LDO (FNP) was considerably greater than Ni/MgAl-LDO (CP) $[23,24]$, and the highest TOF value was obtained at 
$350{ }^{\circ} \mathrm{C}$ of about $0.14 \mathrm{~s}^{-1}$. From Figure $1 \mathrm{~d}$, the $\mathrm{CH}_{4}$ yield of Ni/MgAl-LDO (FNP) reached a maximum value at $350{ }^{\circ} \mathrm{C}$ of about $79.6 \%$. However, that of Ni/MgAl-LDO (CP) reached a maximum at $450{ }^{\circ} \mathrm{C}$ of about $59.8 \%$. Overall, in terms of $\mathrm{CO}$ conversion, $\mathrm{CH}_{4}$ selectivity, and TOF, the catalytic performance of the $\mathrm{Ni} / \mathrm{MgAl}-\mathrm{LDO}$ (FNP) catalyst was clearly superior to that of the Ni/MgAl-LDO (CP) catalyst. Table 1 summarizes $\mathrm{CO}$ methanation from the literature using $\mathrm{Ni} / \mathrm{MgAl}-\mathrm{LDO}$ catalyst systems. The metrics for Ni/MgAl-LDO (CP) and Ni/MgAl-LDO (FNP) catalysts are also shown, which are comparable to those reported in the literature.

X-Ray Diffraction (XRD) was used to characterize the physical structure of the obtained materials and the results are shown in Figure 2. For the precursor supports, there were several diffraction peaks at $11.7^{\circ}, 23.6^{\circ}, 35.2^{\circ}, 39.7^{\circ}, 46.3^{\circ}, 61.3^{\circ}, 62.7^{\circ}, 66.7^{\circ}$, and $75.7^{\circ}$, which were ascribed to the MgAl hydrotalcite phase (JCPDS NO. 22-0452). This indicated that both synthetic methods were effective methods of obtaining hydrotalcite. After being calcined, the characteristic diffraction peaks were observed at $36.9^{\circ}, 42.9^{\circ}, 62.3^{\circ}, 74.7^{\circ}$, and $78.6^{\circ}$, which belong to MgO (PDF \# 45-0946) [25]. There were no obvious peaks for aluminum, probably due to the $\mathrm{Al}$ amorphous lattice of hydrotalcite materials $[19,26]$.
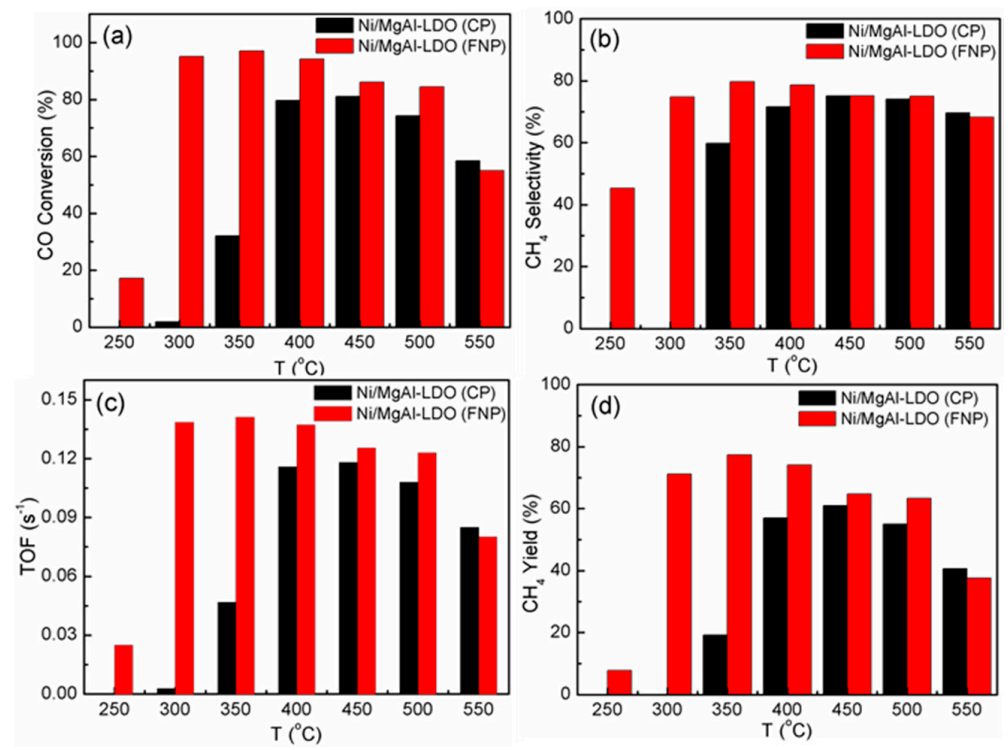

Figure 1. (a) Carbon monoxide (CO) conversion; (b) methane $\left(\mathrm{CH}_{4}\right)$ selectivity values; (c) turnover frequency (TOF) values; (d) $\mathrm{CH}_{4}$ yield of the as-obtained Ni/MgAl-LDO co-precipitation (CP) and $\mathrm{Ni} / \mathrm{MgAl}-\mathrm{LDO}$ flash nano-precipitation (FNP).

Table 1. Comparison of two-dimensional (2D) catalysts prepared via different methods.

\begin{tabular}{|c|c|c|c|c|c|c|c|c|}
\hline 2D Catalysts & $\begin{array}{c}\mathrm{Ni} \\
\text { Content }\end{array}$ & $\begin{array}{l}\text { Preparation } \\
\text { Method }\end{array}$ & $\begin{array}{l}\text { Optimum } \\
\text { Temperature } \\
\left({ }^{\circ} \mathrm{C}\right)\end{array}$ & $\begin{array}{l}\text { Pressure } \\
\text { (Mpa) }\end{array}$ & $\begin{array}{l}\text { Gas Hourly } \\
\text { Space Velocity } \\
\mathrm{mL} \cdot \mathrm{g}^{-1} \cdot \mathrm{h}^{-1}\end{array}$ & $\begin{array}{c}\mathrm{CO} \\
\text { Conversion } \\
(\%)\end{array}$ & $\begin{array}{c}\mathrm{CH}_{4} \\
\text { Selectivity } \\
(\%)\end{array}$ & Reference \\
\hline Ni/VMT (MIAS) & 10 wt. $\%$ & MIAS & 400 & 1.5 & 12,000 & 99.6 & 93.8 & [13] \\
\hline PIM-Ni/PVMT & 0.5 wt. $\%$ & PIM & 450 & 1.5 & 6000 & 93.5 & 64 & [14] \\
\hline NiAl-LDO & $\begin{array}{r}56.5 \\
\text { wt. } \%\end{array}$ & $\begin{array}{c}\text { Urea } \\
\text { hydrolysis }\end{array}$ & 400 & 0.1 & 15,000 & 98 & 92 & [17] \\
\hline NiMg8 & 22 wt. $\%$ & CP method & 400 & 0.1 & 30,000 & 98 & 90 & [18] \\
\hline Ni/VMT-LDO & 10 wt. $\%$ & CP method & 400 & 1.5 & 20,000 & 87.9 & 90 & [19] \\
\hline $\begin{array}{l}\mathrm{Ni} / \mathrm{MgAl}-\mathrm{LDO} \\
\text { (CP) }\end{array}$ & 10 wt. $\%$ & CP method & 450 & 0.1 & 20,000 & 81.12 & 75.14 & This work \\
\hline $\begin{array}{c}\mathrm{Ni} / \mathrm{MgAl}-\mathrm{LDO} \\
\text { (FNP) }\end{array}$ & 10 wt. $\%$ & FNP method & 350 & 0.1 & 20,000 & 97 & 79.76 & This work \\
\hline
\end{tabular}

Note: Vermiculite and plasma-treated vermiculite are abbreviated as VMT and PVMT, respectively; LDO stands for layered double oxide. MIAS, PIM, CP, and FNP are microwave irradiation assisted synthesis, plasma irradiation method, co-precipitation, and flash nanoprecipitation, respectively. 


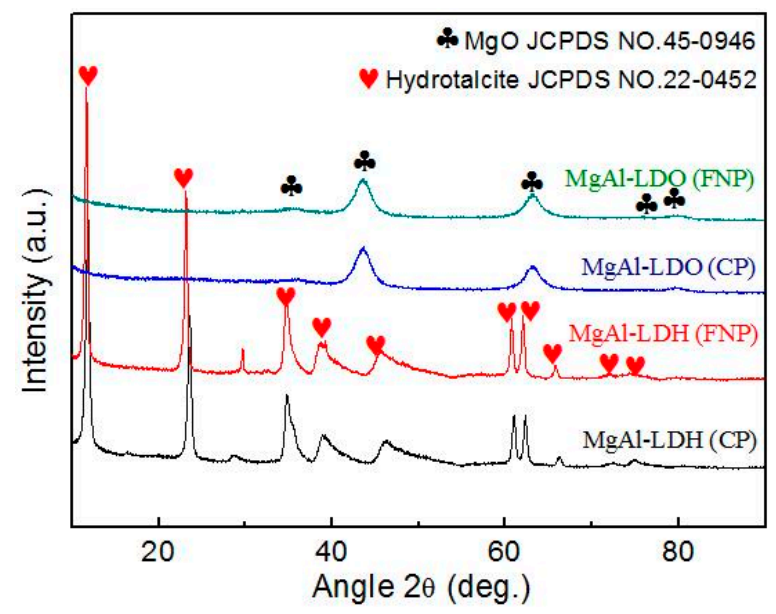

Figure 2. X-ray diffraction (XRD) patterns of MgAl-LDH (CP), MgAl-LDH (FNP), MgAl-LDO (CP), and MgAl-LDO (FNP).

In order to confirm the layered structures of the MgAl-LDO (FNP) and MgAl-LDO (CP), transmission electron microscopy (TEM) and high-resolution TEM (HRTEM) were used to obtain the images, as shown in Figure 3a-d. From the images, both samples exhibited lamination structures, and that of MgAl-LDO (CP) was thicker than the MgAl-LDO (FNP) catalyst. This indicated that the fast mixing speed and violent collision of the FNP method prevented the normal growth cycle of oxide crystals [27].

Figure 3e shows $\mathrm{N}_{2}$ absorption and desorption isotherms of MgAl-LDO (CP) and MgAl-LDO (FNP) catalysts. These were type IV isotherms according to the IUPAC classification, which suggests that the materials were mesoporous [28]. From the pore size distribution curve of the MgAl-LDO $(\mathrm{CP})$, a small peak at 10-70 $\mathrm{nm}$ was observed, and the average pore size was about $21.4 \mathrm{~nm}$. However, the pore size distribution peak was centered at $10-90 \mathrm{~nm}$, and the average pore size was about $19.3 \mathrm{~nm}$. The BET surface areas of MgAl-LDO (FNP) of about $162 \mathrm{~m}^{2} / \mathrm{g}$ was higher than MgAl-LDO (CP) at about $119 \mathrm{~m}^{2} / \mathrm{g}$. Additionally, the pore volume of the MgAl-LDO (FNP) also increased more than that of the sample using the CP method, as shown in Figure 3f. The enhanced pore structure was conducive to gas adsorption as well as heat and mass transfer in the $\mathrm{CO}$ methanation reaction, which was helpful to improve the catalyst efficient [29].

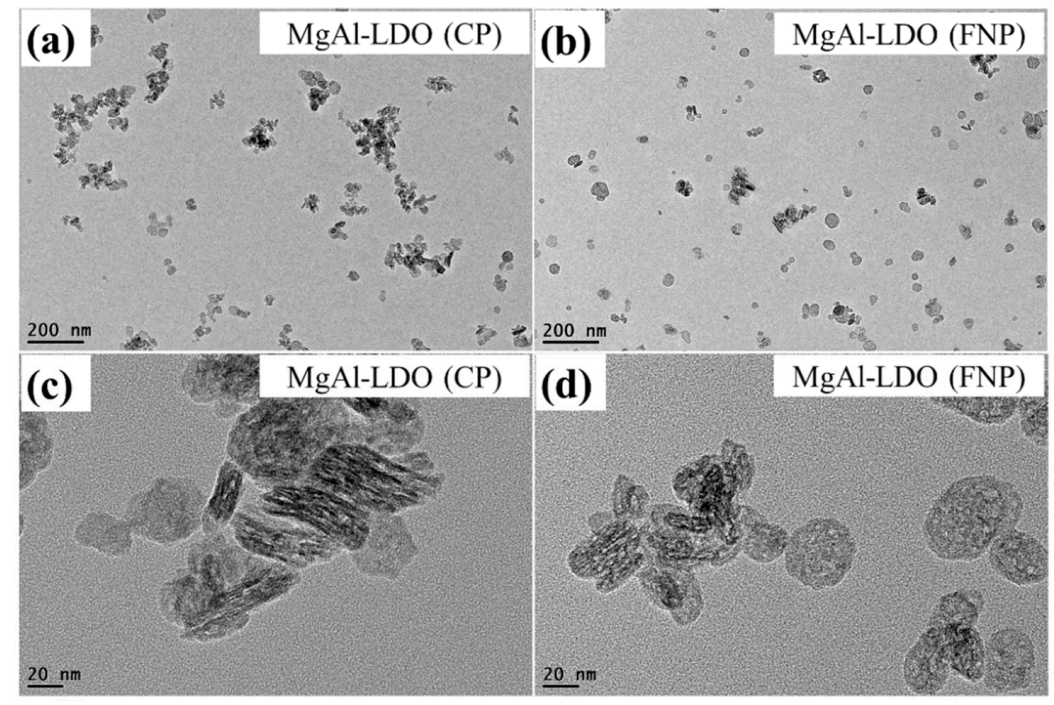

Figure 3. Cont. 

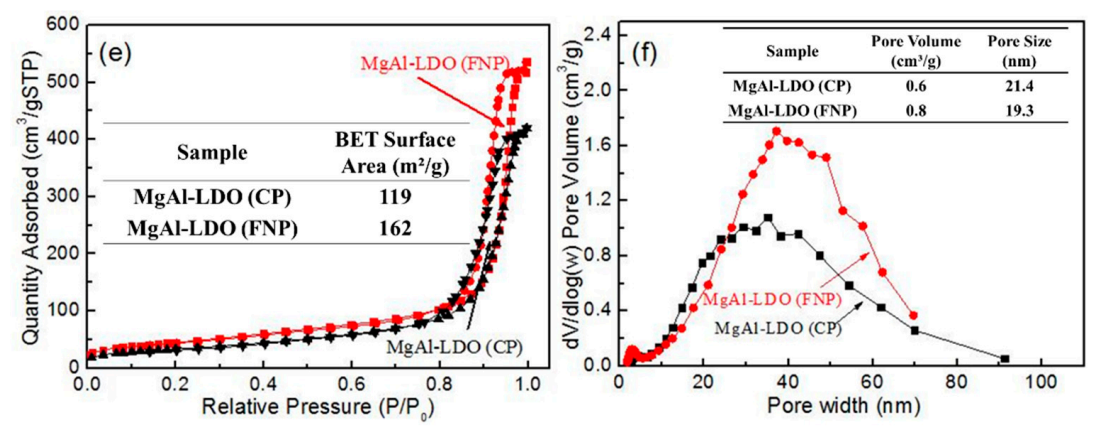

Figure 3. Transmission electron microscopy (TEM) and high-resolution TEM (HRTEM) images of (a,c) MgAl-LDO (CP); (b,d) MgAl-LDO (FNP); atomic force microscopy (AFM) images of (c) MgAl-LDO; (CP) and (d) MgAl-LDO (FNP). (e) $\mathrm{N}_{2}$ adsorption-desorption isotherm. (f) Pore size distribution of $\mathrm{Ni} / \mathrm{MgAl}-\mathrm{LDO}(\mathrm{CP})$ and $\mathrm{Ni} / \mathrm{MgAl}-\mathrm{LDO}(\mathrm{FNP})$.

Atomic force microscopy (AFM) was used to study the thickness of the MgAl-LDO nanosheets, as shown in Figure 4. From previous reports, the AFM images demonstrated obvious bright specks, which represent the nanosheets of the samples [27]. From the results of the corresponding height curves, there was an obvious platform, which is a key characteristic of nanosheets. The thickness of the MgAl-LDO (CP) nanosheets was about $9.0 \mathrm{~nm}$, and that of the MgAl-LDO (FNP) nanosheets was about $4.5 \mathrm{~nm}$. This indicated that the hydrotalcate materials obtained using the FNP method prevented the accumulation of nanosheets, and resulted in thinner nanosheets, thereby improving the dispersion of $\mathrm{Ni}$ and offering many more active sites [30,31].
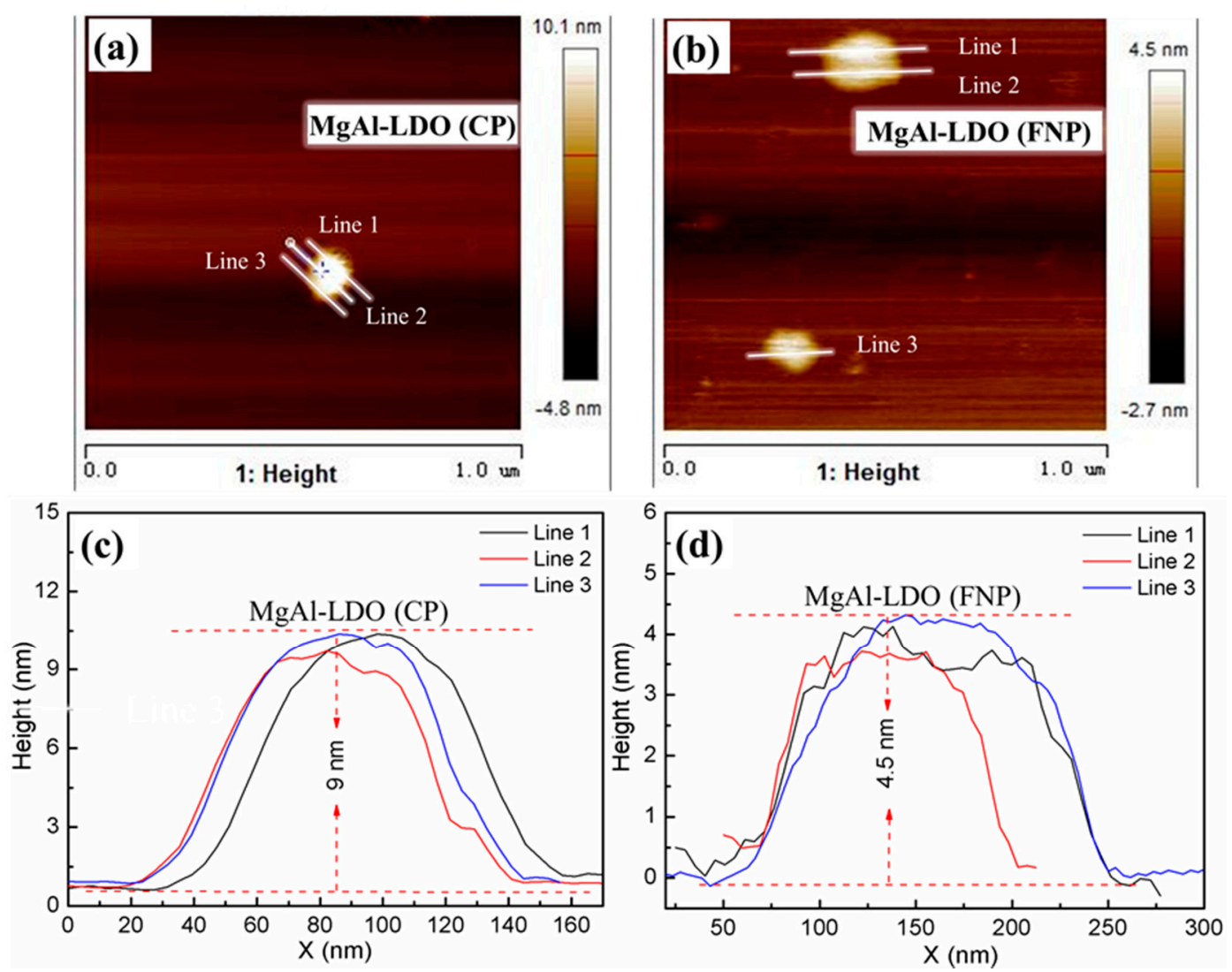

Figure 4. AFM images of (a) MgAl-LDO (CP), (b) MgAl-LDO (FNP) nanosheets, and the corresponding height curves of (c) MgAl-LDO (CP) and (d) MgAl-LDO (FNP). 
X-ray photoelectron spectroscopy (XPS) was used to study the surface chemical composition and valence states of elements in the supports, as shown in Figure 5. From Figure 5a, there were obvious characteristic peaks of $\mathrm{Al}, \mathrm{O}$, and $\mathrm{Mg}$ elements in both samples. The peaks at $1303.3 \mathrm{eV}$ and $1302.9 \mathrm{eV}$ were attributed to the Mg1s spectrum of MgAl-LDO (CP) and MgAl-LDO (FNP) samples, respectively, as shown in Figure $5 b$. For the $\mathrm{Al} 2 \mathrm{p}$ orbitals, the spectra peaks of MgAl-LDO (CP) and MgAl-LDO (FNP) samples appeared at $73.6 \mathrm{eV}$ and $73.9 \mathrm{eV}$, respectively, as shown in Figure 5c. Compared with $\mathrm{MgAl}-\mathrm{LDO}(\mathrm{CP})$, the small peak shift toward higher binding energies for both $\mathrm{Mg}(0.4 \mathrm{eV})$ and $\mathrm{Al}$ $(0.3 \mathrm{eV})$ suggested a decrease in the oxidation state of the transition metals [32]. From the findings, the XPS peak migration of metal oxides caused the lattice distortion of metal, which resulted in more defective sites and active sites [33,34]. Additionally, the introduction of oxygen vacancies was balanced by the lowered valence state of $\mathrm{Mg}$ and $\mathrm{Al}$ sites.
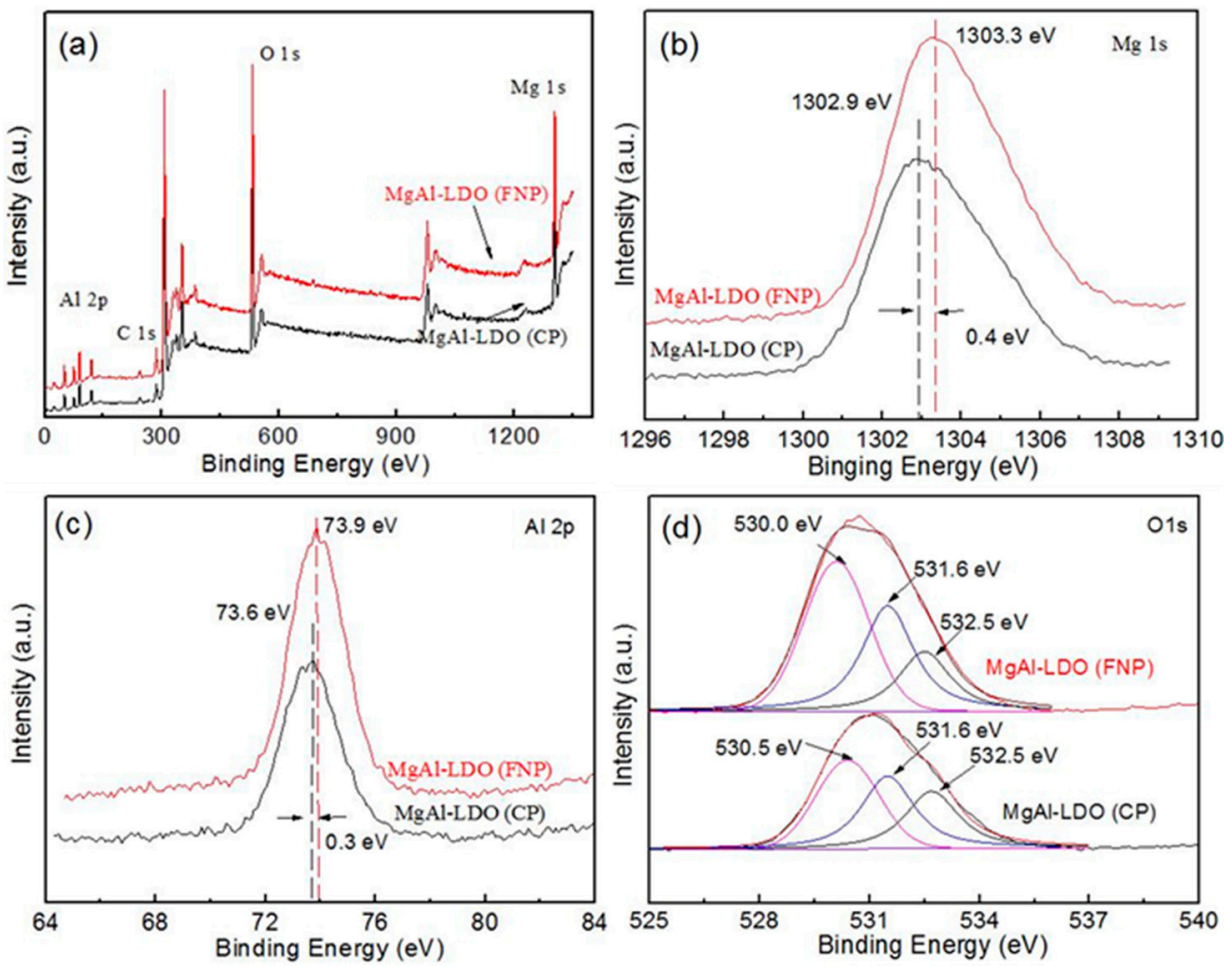

Figure 5. X-ray photoelectron spectroscopy (XPS) spectra of the as-obtained MgAl-LDO (CP) and MgAl-LDO (FNP). (a) Survey spectra, (b) Mg, (c) Al, and (d) O.

The $\mathrm{O} 1 \mathrm{~s}$ peaks of the samples were divided into three peaks at about $530 \mathrm{eV}, 531 \mathrm{eV}$, and $532 \mathrm{eV}$, as shown in Figure $5 \mathrm{~d}$. The peak at $530 \mathrm{eV}$ was attributed to lattice oxygen from metallic oxide; the peak at $531 \mathrm{eV}$ was attributed to the adsorbed oxygen from adsorbed $\mathrm{H}_{2} \mathrm{O}, \mathrm{CO}_{2}$, and $\mathrm{O}_{2}$; and the peak at $532 \mathrm{eV}$ was attributed to surface oxygen from the -OH species [35,36]. From the diffraction pattern, the lattice oxygen peak area of MgAl-LDO (FNP) was bigger than that of MgAl-LDO (CP). This indicated that more oxygen vacancies existed on the surface of the MgAl-LDO (FNP) [37]. The abundant lattice oxygen provided external assistance to complete the oxygen cycle during the catalytic reaction [33].

After loading the active component $\mathrm{Ni}, \mathrm{XRD}$ of the as-obtained materials was further characterized and the results are shown in Figure 6. The diffraction pattern of the Ni/MgAl-LDH (CP) and $\mathrm{Ni} / \mathrm{MgAl}-\mathrm{LDH}(\mathrm{FNP})$ materials highlights a hydrotalcite structure at $2 \theta=11.7^{\circ}, 23.6^{\circ}, 35.2^{\circ}, 39.7^{\circ}$, $46.3^{\circ}, 61.3^{\circ}, 62.7^{\circ}, 66.7^{\circ}$, and $75.7^{\circ}$, which were ascribed to the MgAl hydrotalcite phase (JCPDS NO. 22-0452) [38]. This confirmed that MgAl-LDO transformed into MgAl-LDH via the nickel solution treatment. The diffraction pattern of the Ni/MgAl-LDO (CP) and Ni/MgAl-LDO (FNP) materials 
showed clear diffraction peaks corresponding to the $\mathrm{MgO}$ phase, including peaks at $36.9^{\circ}, 42.9^{\circ}$, $62.3^{\circ}, 74.7^{\circ}$, and $78.6^{\circ}$ corresponding to $\mathrm{MgO}$ (PDF \# 45-0946) [39]. There were no obvious peaks for nickel and aluminum, which was probably because nickel and aluminum were not detected in the hydrotalcite lattice or $\mathrm{NiO}$ was well-dispersed on the catalyst surface [18].

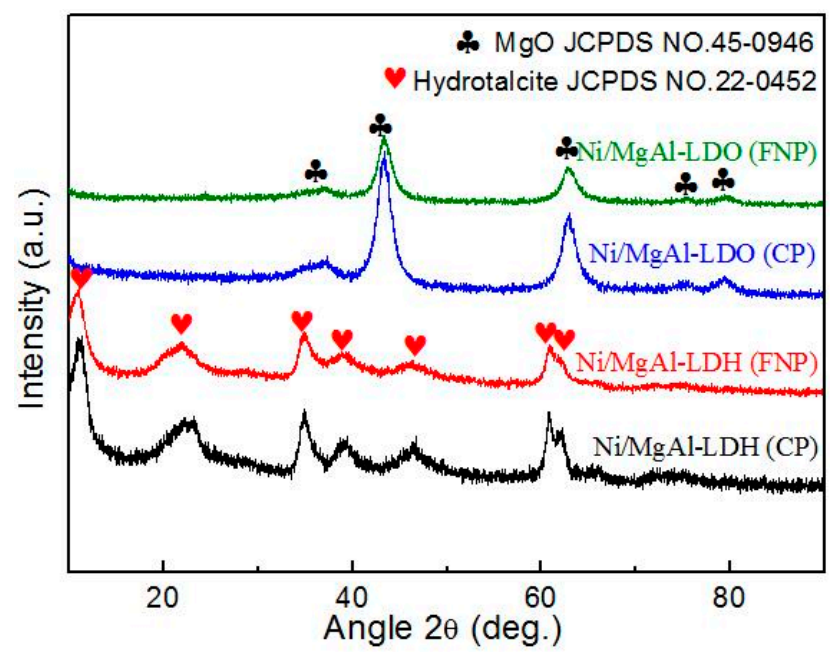

Figure 6. XRD patterns of Ni/MgAl-LDH (CP), Ni/MgAl-LDH (FNP), Ni/MgAl-LDO (CP), and $\mathrm{Ni} / \mathrm{MgAl}-\mathrm{LDO}$ (FNP).

Figure $7 \mathrm{a}-\mathrm{d}$ show the TEM and HRTEM images of the Ni/MgAl-LDO (CP) and Ni/MgAl-LDO (FNP) catalysts. The layered structure of the supports was damaged after high temperature treatment. From Figure 7e, Ni/MgAl-LDO (CP) and Ni/MgAl-LDO (FNP) catalysts presented two type IV isotherms, which were is the key feature of mesoporous materials. The BET surface areas of $\mathrm{Ni} / \mathrm{MgAl}-\mathrm{LDO}(\mathrm{CP})$ and Ni/MgAl-LDO (FNP) were $218 \mathrm{~m}^{2} / \mathrm{g}$ and $214 \mathrm{~m}^{2} / \mathrm{g}$, respectively. The slight increasing BET surface area of $\mathrm{Ni} / \mathrm{MgAl}-\mathrm{LDO}(\mathrm{CP})$ might be due to the tiny pores produced via $\mathrm{Ni} / \mathrm{MgAl}-\mathrm{LDO}$ transferred from $\mathrm{Ni} / \mathrm{MgAl}-\mathrm{LDH}$ (i.e., Ni-MgAl-LDH). The Ni/MgAl-LDH was easily formed from MnAl-LDO when added to $\mathrm{Ni}\left(\mathrm{NO}_{3}\right)_{2} \cdot 6 \mathrm{H}_{2} \mathrm{O}$ solution in the impregnation progress. Figure $7 \mathrm{f}$ shows that the pore volume and pore size of Ni/MgAl-LDO (CP) were $0.5 \mathrm{~cm}^{3} / \mathrm{g}$ and $10.2 \mathrm{~nm}$, respectively. The corresponding MgAl-LDO (FNP) values were $0.4 \mathrm{~cm}^{3} / \mathrm{g}$ and $7.4 \mathrm{~nm}$, which agreed with the HRTEM images results [18].

The XPS diffraction curves of the obtained materials are shown in Figure 8. For both samples, the peaks with a binding energy of $853 \mathrm{eV}$ were attributed to $\mathrm{Ni}^{0}$. The peaks at $856.2 \mathrm{eV}$ and $862.7 \mathrm{eV}$ were assigned to Ni 2p3/2 and satellite peak, respectively. Similarly, the two peaks with binding energies of $873.7 \mathrm{eV}$ and $879.6 \mathrm{eV}$ were assigned to $\mathrm{Ni2} 1 / 2$ and its satellite peak for Ni/MgAl-LDO (CP) and Ni/MgAl-LDO (FNP), respectively [40]. From Table 2, the proportion of Ni content was about $1.85 \%$ for the amount of elements on the Ni/MgAl-LDO (FNP) surface, and that of Ni/MgAl-LDO (CP) was $1.16 \%$. This suggested that $\mathrm{Ni}$ was easily exposed to the catalyst surface via the FNP method, which was conducive to surface catalytic reaction. Furthermore, the radio of $\mathrm{Ni}^{0} / \mathrm{Ni}$ and $\mathrm{Ni}^{2+} / \mathrm{Ni}$ were about $4.7 \%$ and $48.6 \%$ for $\mathrm{Ni} / \mathrm{MgAl}-\mathrm{LDO}$ (FNP), respectively, which were higher than for $\mathrm{Ni} / \mathrm{MgAl}-\mathrm{LDO}$ (CP) at $4.0 \%$ and $42.6 \%$. The abundant $\mathrm{Ni}^{0}$ and $\mathrm{Ni}^{2+}$ played a key role in the $\mathrm{CO}$ methanation reaction.

Notably, after loading the $\mathrm{Ni}$, the peak shift to higher binding energies of Ni/MgAl-LDO (FNP) was still evident. In other words, more violent lattice distortion of metal existed on the surface of the Ni/MgAl-LDO (FNP) than the Ni/MgAl-LDO (CP) catalysts, which suggested that there were abundant oxygen vacancies for $\mathrm{Ni} / \mathrm{MgAl}-\mathrm{LDO}$ (FNP) [41]. 


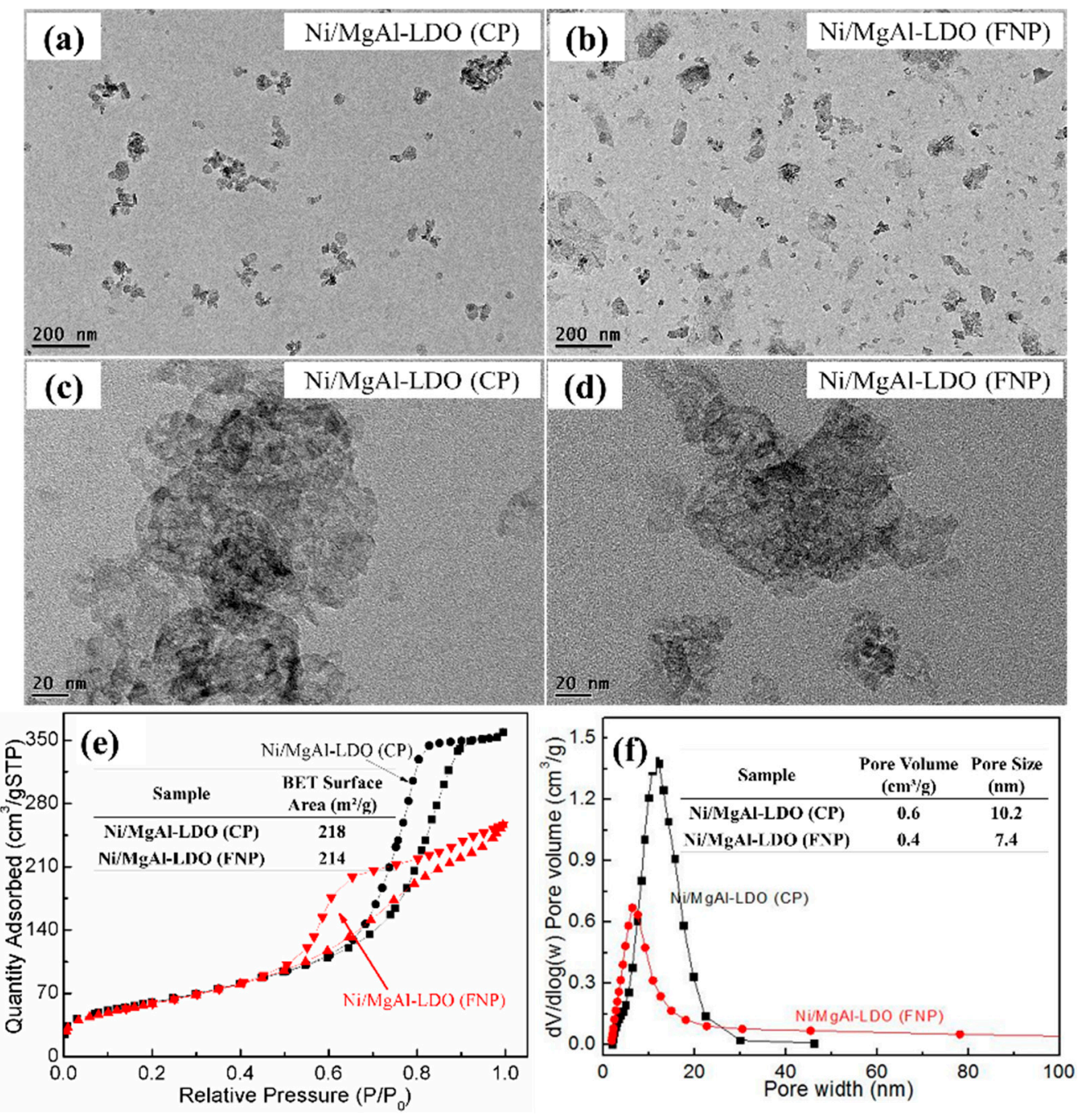

Figure 7. TEM and HRTEM images of (a,c) Ni/MgAl-LDO (CP), (b,d) Ni/MgAl-LDO (FNP). (e) $\mathrm{N}_{2}$ adsorption-desorption isotherm for Ni/MgAl-LDO (CP) and Ni/MgAl-LDO (FNP). (f) Pore size distribution of $\mathrm{Ni} / \mathrm{MgAl}-\mathrm{LDO}(\mathrm{CP})$ and $\mathrm{Ni} / \mathrm{MgAl}-\mathrm{LDO}(\mathrm{FNP})$.

Table 2. Elemental analysis of $\mathrm{Ni}, \mathrm{Mg}, \mathrm{Al}$, and $\mathrm{O}$ elements content by $\mathrm{X}$-ray photoelectron spectroscopy (XPS).

\begin{tabular}{ccccccc}
\hline Sample & $\mathbf{N i}(\mathbf{\%})$ & $\mathbf{N i}^{\mathbf{0}} \mathbf{N i} \mathbf{( \% )}$ & $\mathbf{N i}^{\mathbf{2 +}} / \mathbf{N i} \mathbf{( \% )}$ & $\mathbf{M g} \mathbf{( \% )}$ & $\mathbf{A l ~ ( \% )}$ & $\mathbf{O}(\mathbf{\%})$ \\
\hline MgAl-LDO (CP) & - & - & & 17.86 & 13.06 & 53.90 \\
Ni/MgAl-LDO (CP) & 1.16 & 4.0 & 42.6 & 19.08 & 16.66 & 51.80 \\
MgAl-LDO (FNP) & - & - & & 15.68 & 14.45 & 53.72 \\
Ni/MgAl-LDO & 1.85 & 4.7 & 48.6 & 14.77 & 18.60 & 51.44 \\
(FNP) & & & & & & \\
\hline
\end{tabular}



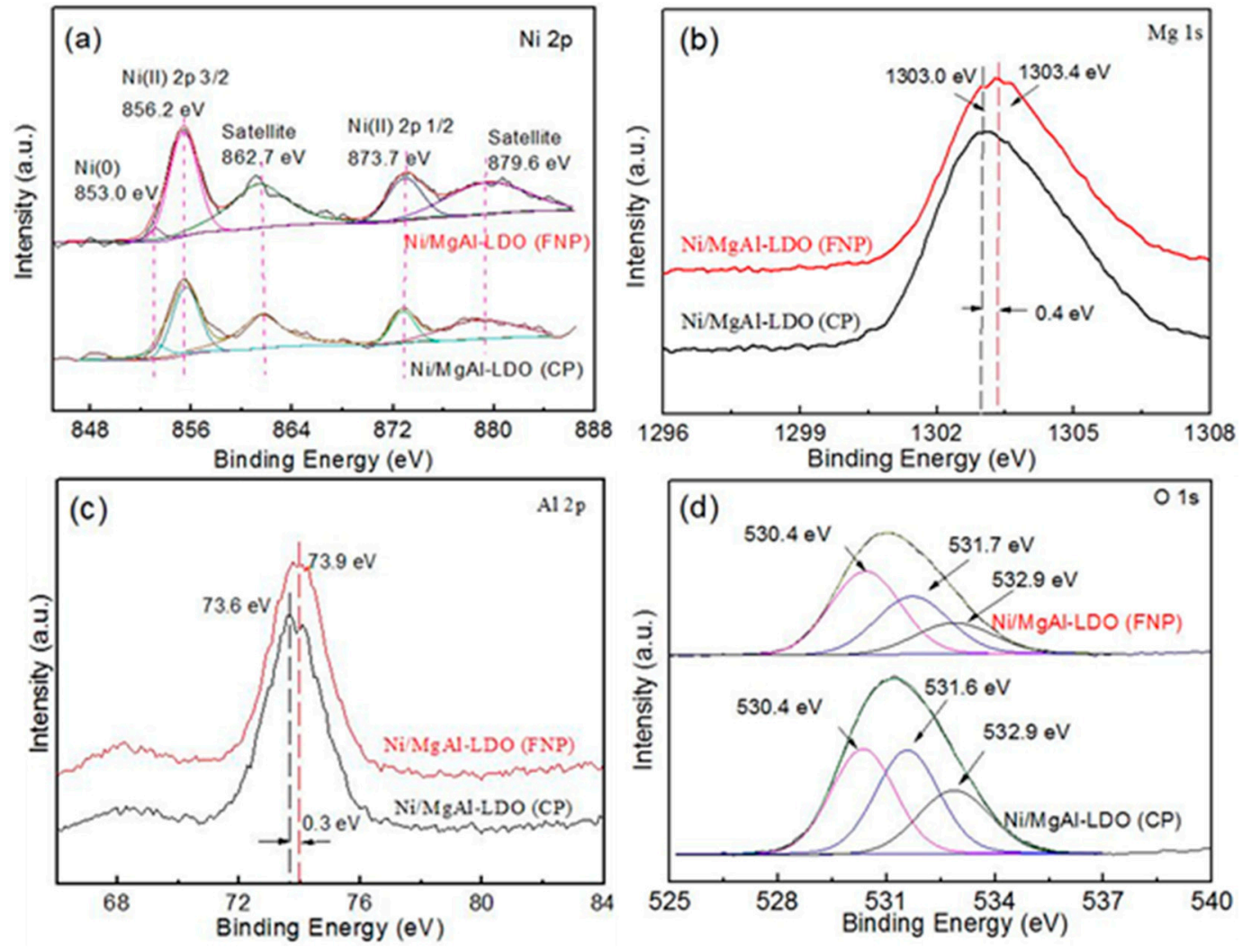

Figure 8. XPS spectra of the as-obtained Ni/MgAl-LDO (CP) and Ni/MgAl-LDO (FNP): (a) Ni, (b) Mg, (c) $\mathrm{Al}$, and (d) $\mathrm{O}$.

\section{Materials and Methods}

\subsection{Coprecipitation Method}

The requisite quantities of $\mathrm{Al}\left(\mathrm{NO}_{3}\right)_{3} \cdot 9 \mathrm{H}_{2} \mathrm{O}$ as the $\mathrm{Al}$ source, $\mathrm{Mg}\left(\mathrm{NO}_{3}\right)_{2} \cdot 4 \mathrm{H}_{2} \mathrm{O}$ as the $\mathrm{Mg}$ source, were dissolved in distilled water separately to obtain metal precursor solution, where the $\mathrm{Mg}: \mathrm{Al}$ molar ratio was $2: 1$. The $1.0 \mathrm{~mol} / \mathrm{L}$ mixed solution with a $1.5: 1$ molar ratio of $\mathrm{NaOH}: \mathrm{NaHCO}_{3}$ as the precipitant was added into the precursor solution, where the index of the salt-alkali ratio was 1:4, and was stirred for $1 \mathrm{~h}$. The precipitate was aged for $24 \mathrm{~h}$ at $65^{\circ} \mathrm{C}$, and then washed several times with deionized water to keep the mixed solution $\mathrm{pH}$ at 7, and then dried in an oven to obtain MgAl-LDH (CP) at $80{ }^{\circ} \mathrm{C}$ for $12 \mathrm{~h}$. The obtained materials were calcined in a muffle furnace at $550{ }^{\circ} \mathrm{C}$ for $4 \mathrm{~h}$ to obtain MgAl-LDO (CP).

For the Ni/MgAl-LDO (CP) catalyst, requisite quantities of $\mathrm{Ni}\left(\mathrm{NO}_{3}\right)_{2} \cdot 6 \mathrm{H}_{2} \mathrm{O}$ were dissolved in distilled water, and the MgAl-LDO (CP), as the support, was added into the obtained solution, where the Ni loading was $10 \%$. After stirring for $12 \mathrm{~h}$, the obtained material was placed in an $80{ }^{\circ} \mathrm{C}$ water bath for $2 \mathrm{~h}$ to evaporate water. Then, the sample was dried in an oven at $80^{\circ} \mathrm{C}$ for $12 \mathrm{~h}$, and the as-prepared precursor calcined at $550{ }^{\circ} \mathrm{C}$ for $4 \mathrm{~h}$ to obtain NiO/MgAl-LDO (CP). The as-obtained $\mathrm{NiO} / \mathrm{MgAl}-\mathrm{LDO}(\mathrm{CP})$ was reduced by in situ reduction to produce $\mathrm{Ni} / \mathrm{MgAl}-\mathrm{LDO}(\mathrm{CP})$ catalyst.

\subsection{Flashnano-Precipitation (FNP) Method}

The metal precursor solution and precipitant, as shown in Section 3.1., were injected into separate syringes. The liquid flow rate was controlled by the FNP equipment, and the as-raw materials crashed heavily in the FNP platform to produce the precipitate. Before the experiment, liquid flow rate was adjusted over several iterations to control the 1:4 salt-alkali ratio. The resulting precipitate was aged for $24 \mathrm{~h}$ at $65^{\circ} \mathrm{C}$ and then filtered and washed several times with distilled water until there was no $\mathrm{pH}$ 
change $(\mathrm{pH}=7)$. Finally, the precipitate was dried in an oven to obtain MgAl-LDH (FNP) at $80^{\circ} \mathrm{C}$ for $12 \mathrm{~h}$. The obtained materials were calcined in a muffle furnace at $550{ }^{\circ} \mathrm{C}$ for $4 \mathrm{~h}$ to obtain MgAl-LDO (FNP). The NiO/MgAl-LDH (FNP), and Ni/MgAl-LDO (FNP), as described in Section 3.1.

\subsection{Catalyst Characterization}

The crystallographic properties of the supports and catalysts were determined through XRD analysis. The X-ray diffraction (XRD) patterns were obtained with a BrukerD8 Advance X-ray diffractometer (Bruker Biosciences Corporation, Billerica, MA, USA) with $\mathrm{Cu} K \alpha$ radiation in the $2 \theta$ range of 0 to $90^{\circ}$. Transmission electron microscopy (TEM) and high-resolution TEM (HRTEM) investigations used a Tecnai F30 field-emission TEM (TecnaiG2 F20, FEI Instrument Ltd., Hillsboro, OR, USA). The support and catalysts were analysed by nitrogen physisorption at $77 \mathrm{~K}$ using Brunauer-Emmett-Teller (BET) (Micromeritics Instrument Ltd., Norcross, GA, USA) to calculate the surface area, pore volume, and pore size. The structures of the as-synthesized samples were elucidated via atomic force microscopy (AFM) with a Bruker Multimode 8 (Multimode 8, Bruker, Billerica, MA, USA). X-ray photoelectron spectroscopy (XPS) experiments used a Thermo ESCALAB 250XIelectron spectrometer from Kratos Analytical with $\mathrm{Mg} \mathrm{K} \alpha(20 \mathrm{~mA}, 12 \mathrm{kV})$ radiation (Escalab 250Xi, Thermo Fisher Scientific, Waltham, MA, USA).

\subsection{Activity Measurement}

Experiments to determine the catalytic performance of the catalysts were evaluated by a fixed bed microreactor. In the test, a sample catalyst (about $0.2 \mathrm{~g}$ ) was placed in a stainless steel tubular microreactor with a weight hourly space velocity (WHSV) of $20,000 \mathrm{~mL} \cdot \mathrm{g}^{-1} \cdot \mathrm{h}^{-1}$. First, the sample was purged with $\mathrm{N}_{2}$ at $60 \mathrm{~mL} \cdot \mathrm{min}^{-1}$, and then the sample was heated to $500{ }^{\circ} \mathrm{C}$. Next, the sample was reduced with $60 \mathrm{~mL} \cdot \mathrm{min}^{-1} \mathrm{H}_{2}$ for $2 \mathrm{~h}$ to produce the as-needed catalyst. Then, the temperature was cooled down to $250{ }^{\circ} \mathrm{C}$, and syngas $\left(\mathrm{H}_{2}: \mathrm{CO}\right.$ ratio of 3:1) was introduced into the microreactor at atmospheric pressure. The outlet gases were analyzed online every $50{ }^{\circ} \mathrm{C}$ between 250 and $550{ }^{\circ} \mathrm{C}$ by gas chromatography (GC-2014C, SHIMADZU, Kyoto, Japan).

\section{Conclusions}

Oxygen vacancies were introduced to the $\mathrm{Ni} / \mathrm{MgAl}-\mathrm{LDO}$ (FNP) via the FNP method to produce a highly-efficient catalyst for CO methanation. XPS analysis suggested that the FNP method produced more active sites, which was demonstrated by the remarkable $\mathrm{CO}$ conversion and $\mathrm{CH}_{4}$ selectivity. The Ni/MgAl-LDO (FNP) exhibited a high CO conversion of $97 \%, \mathrm{CH}_{4}$ selectivity of $79.8 \%$, a turnover frequency (TOF) of $0.141 \mathrm{~s}^{-1}$, and a $\mathrm{CH}_{4}$ yield of $77.4 \%$ at $350^{\circ} \mathrm{C}$. The weight hourly space velocity was $20,000 \mathrm{~mL} \cdot \mathrm{g}^{-1} \cdot \mathrm{h}^{-1}$, with a synthesis gas flow rate of $65 \mathrm{~mL} \cdot \mathrm{min}^{-1}$, and a pressure of $1 \mathrm{~atm}$. For the $\mathrm{Ni} / \mathrm{MgAl}-\mathrm{LDO}(\mathrm{CP})$ catalyst, this material exhibited a CO conversion of $81.1 \%$, a $\mathrm{CH}_{4}$ selectively of $75.1 \%$, a TOF of $0.118 \mathrm{~s}^{-1}$, and a $\mathrm{CH}_{4}$ yield of $61 \%$ at $450{ }^{\circ} \mathrm{C}$. This study demonstrates that MgAl-LDO could become an important catalyst. The FNP method offers a new strategy to easily and rapidly obtain catalysts with many oxygen vacancies.

Author Contributions: F.Y., Q.W. and X.G. designed and administered the experiments. M.Z. (Mengjuan Zhang) performed experiments. M.Z. (Mengjuan Zhang), J.L., K.C., Y.Y., P.L., M.Z. (Mingyuan Zhu) and Y.S. collected and analyzed data. All authors discussed the data and wrote the manuscript.

Acknowledgments: This work was financially supported by National Natural Science Foundation of China (U1203293), and Program for Changjiang Scholars and Innovative Research Team in University (No. IRT_15R46), and the Program of Science and Technology Innovation Team in Bingtuan (No. 2015BD003).

Conflicts of Interest: The authors declare no conflicts of interests. 


\section{References}

1. Tao, M.; Meng, X.; Xin, Z.; Bian, Z.; Lv, Y.; Gu, J. Synthesis and characterization of well dispersed nickel-incorporated SBA-15 and its high activity in syngas methanation reaction. Appl. Catal. A Gen. 2016, 516, 127-134. [CrossRef]

2. Liu, Q.; Gu, F.; Lu, X.; Liu, Y.; Li, H.; Zhong, F.; Xu, G.; Su, F. Enhanced catalytic performances of $\mathrm{Ni}_{1} / \mathrm{Al}_{2} \mathrm{O}_{3}$ catalyst via addition of $\mathrm{V}_{2} \mathrm{O}_{3}$ for $\mathrm{CO}$ methanation. Appl. Catal. A Gen. 2014, 488, 37-47. [CrossRef]

3. Zhang, M.; Li, P.; Tian, Z.; Zhu, M.; Wang, F.; Li, J.; Dai, B.; Yu, F.; Qiu, H.; Gao, H. Clarification of Active Sites at Interfaces between Silica Support and Nickel Active Components for Carbon Monoxide Methanation. Catalysts 2018, 8, 293. [CrossRef]

4. Liu, Q.; Zhong, Z.; Gu, F.; Wang, X.; Lu, X.; Li, H.; Xu, G.; Su, F. CO methanation on ordered mesoporous $\mathrm{Ni}-\mathrm{Cr}-\mathrm{Al}$ catalysts: Effects of the catalyst structure and $\mathrm{Cr}$ promoter on the catalytic properties. J. Catal. 2016, 337, 221-232. [CrossRef]

5. Liu, Q.H.; Dong, X.F.; Lin, W.M. Highly selective $\mathrm{CO}$ methanation over amorphous $\mathrm{Ni}-\mathrm{Ru}-\mathrm{B} / \mathrm{ZrO}_{2}$ catalyst. Chin. Chem. Lett. 2009, 20, 889-892. [CrossRef]

6. Li, S.; Jin, H.; Gao, L.; Zhang, X. Exergy analysis and the energy saving mechanism for coal to synthetic/substitute natural gas and power cogeneration system without and with $\mathrm{CO}_{2}$ capture. Appl. Energy 2014, 130, 552-561. [CrossRef]

7. Kopyscinski, J.; Schildhauer, T.J.; Biollaz, S.M.A. Production of synthetic natural gas (SNG) from coal and dry biomass-A technology review from 1950 to 2009. Fuel 2010, 89, 1763-1783. [CrossRef]

8. Chen, X.; Jin, J.; Sha, G.; Li, C.; Zhang, B.; Su, D.; Williams, C.T.; Liang, C. Silicon-nickel intermetallic compounds supported on silica as a highly efficient catalyst for CO methanation. Catal. Sci. Technol. 2013, 4, 53-61. [CrossRef]

9. Lv, Y.; Xin, Z.; Meng, X.; Tao, M.; Bian, Z.; Gu, J.; Gao, W. Essential role of organic additives in preparation of efficient Ni/KIT-6 catalysts for CO methanation. Appl. Catal. A Gen. 2018, 558, 99-108. [CrossRef]

10. Dan, J.; Huang, X.; Li, P.; Zhang, Y.; Zhu, M.; Guo, X.; Dai, B.; Wang, Q.; Yu, F. Two-Dimensional Porous Silica Nanomesh from Expanded Multilayered Vermiculite via Mixed Acid Leaching. Nanosci. Nanotechnol. Lett. 2016, 8, 1028-1032. [CrossRef]

11. Li, P.; Zhu, M.; Dan, J.; Kang, L.; Lai, L.; Cai, X.; Zhang, J.; Yu, F.; Tian, Z.; Dai, B. Two-dimensional porous $\mathrm{SiO}_{2}$ nanomesh supported high dispersed Ni nanoparticles for $\mathrm{CO}$ methanation. Chem. Eng. J. 2017, 326, 774-780. [CrossRef]

12. Xin, H.; Yu, F.; Zhu, M.-Y.; Ouyang, F.-H.; Dai, B.; Dan, J.-M. Hydrochlorination of acetylene using expanded multilayered vermiculite (EML-VMT)-supported catalysts. Chin. Chem. Lett. 2015, 26, 1101-1104.

13. Li, P.; Wen, B.; Yu, F.; Zhu, M.; Guo, X.; Han, Y.; Kang, L.; Huang, X.; Dan, J.; Ouyang, F.; et al. High efficient nickel/vermiculite catalyst prepared via microwave irradiation-assisted synthesis for carbon monoxide methanation. Fuel 2016, 171, 263-269. [CrossRef]

14. Zhang, M.; Li, P.; Zhu, M.; Tian, Z.; Dan, J.; Li, J.; Dai, B.; Yu, F. Ultralow-weight loading Ni catalyst supported on two-dimensional vermiculite for carbon monoxide methanation. Chin. J. Chem. Eng. 2018. [CrossRef]

15. Li, P.; Yu, F.; Altaf, N.; Zhu, M.; Li, J.; Dai, B.; Wang, Q. Two-Dimensional Layered Double Hydroxides for Reactions of Methanation and Methane Reforming in C1 Chemistry. Materials 2018, 11, 221. [CrossRef] [PubMed]

16. Jiří, R.; Günter, S.E.; Jindřich, S.; Arnošt, Z. Supported nickel catalyst from hydroxycarbonate of nickel and aluminium. Chem. Eng. Technol. 1994, 17, 41-46.

17. Bian, L.; Wang, W.; Xia, R.; Li, Z.H. Ni-based catalyst derived from Ni/Al hydrotalcite-like compounds by urea hydrolysis method for CO methanation. RSC Adv. 2015, 6, 677-686. [CrossRef]

18. Li, Z.; Bian, L.; Zhu, Q.; Wang, W. Ni-based catalyst derived from Ni/Mg/Al hydrotalcite-like compounds and its activity in the methanation of carbon monoxide. Kinet. Catal. 2014, 55, 217-223. [CrossRef]

19. Li, P.; Zhu, M.; Tian, Z.; Han, Y.; Zhang, Y.; Zhou, T.; Kang, L.; Dan, J.; Guo, X.; Yu, F.; et al. Two-Dimensional Layered Double Hydroxide Derived from VermiculiteWaste Water Supported Highly Dispersed Ni Nanoparticles for CO Methanation. Catalysts 2017, 7, 79. [CrossRef]

20. Wang, C.; Yu, F.; Zhu, M.; Shi, Y.; Dan, J.; Lv, Y.; Guo, X.; Dai, B. Up-scaled flash nano-precipitation production route to develop a $\mathrm{MnO}_{\mathrm{x}}-\mathrm{CeO}_{2}-\mathrm{Al}_{2} \mathrm{O}_{3}$ catalyst with enhanced activity and $\mathrm{H}_{2} \mathrm{O}$ resistant performance for $\mathrm{NO}_{x}$ selective catalytic reduction with $\mathrm{NH}_{3}$. Chem. Eng. Res. Des. 2018, 134, 476-486. [CrossRef] 
21. Wang, M.; Yang, N.; Guo, Z.; Gu, K.; Shao, A.; Zhu, W.; Xu, Y.; Wang, J.; Prud'homme, R.K.; Guo, X. Facile Preparation of AIE-Active Fluorescent Nanoparticles through Flash Nanoprecipitation. Ind. Eng. Chem. Res. 2015, 54, 4683-4688. [CrossRef]

22. Zhao, D.; Wang, C.; Yu, F.; Shi, Y.; Cao, P.; Dan, J.; Chen, K.; Lv, Y.; Guo, X.; Dai, B. Enhanced Oxygen Vacancies in a Two-Dimensional MnAl-Layered Double Oxide Prepared via Flash Nanoprecipitation Offers High Selective Catalytic Reduction of $\mathrm{NO}_{x}$ with $\mathrm{NH}_{3}$. Nanomaterials 2018, 8, 620. [CrossRef] [PubMed]

23. Kadirvelu, K.; Thamaraiselvi, K.; Namasivayam, C. Removal of heavy metals from industrial wastewaters by adsorption onto activated carbon prepared from an agricultural solid waste. Bioresour. Technol. 2001, 76, 63-65. [CrossRef]

24. Gao, Y.; Meng, F.; Ji, K.; Song, Y.; Li, Z. Slurry phase methanation of carbon monoxide over nanosized $\mathrm{Ni}-\mathrm{Al}_{2} \mathrm{O}_{3}$ catalysts prepared by microwave-assisted solution combustion. Appl. Catal. A Gen. 2016, 510, 74-83. [CrossRef]

25. Lim, Y.S.; Moon, D.J.; Park, N.C.; Shin, J.S.; Kim, J.H.; Kim, Y.C. Autothermal reforming of propane over hydrotalcite-like catalysts containing promotor. J. Nanosci. Nanotechnol. 2007, 7, 4009-4012. [CrossRef] [PubMed]

26. Zhang, X.; Chen, X.; Jin, S.; Peng, Z.; Liang, C. Ni $/ \mathrm{Al}_{2} \mathrm{O}_{3}$ Catalysts Derived from Layered Double Hydroxide and Their Applications in Hydrodeoxygenation of Anisole. Communication 2016, 1, 577-584.

27. Hwang, S.; Lee, J.; Hong, U.G.; Baik, J.H.; Koh, D.J.; Lim, H.; Song, I.K. Methanation of carbon dioxide over mesoporous $\mathrm{Ni}-\mathrm{Fe}-\mathrm{Ru}-\mathrm{Al}_{2} \mathrm{O}_{3}$ xerogel catalysts: Effect of ruthenium content. J. Ind. Eng. Chem. 2013, 19, 698-703. [CrossRef]

28. Liu, Q.; Qiao, Y.; Tian, Y.; Gu, F.; Zhong, Z.; Su, F. Ordered Mesoporous Ni-Fe-Al Catalysts for CO Methanation with Enhanced Activity and Resistance to Deactivation. Ind. Eng. Chem. Res. 2017, 56, 9809-9820. [CrossRef]

29. Cao, F.; Su, S.; Xiang, J.; Wang, P.Y.; Hu, S.; Sun, L.S.; Zhang, A.C. The activity and mechanism study of $\mathrm{Fe}-\mathrm{Mn}-\mathrm{Ce} /$ gamma- $\mathrm{Al}_{2} \mathrm{O}_{3}$ catalyst for low temperature selective catalytic reduction of $\mathrm{NO}$ with $\mathrm{NH}_{3}$. Fuel 2015, 139, 232-239. [CrossRef]

30. Wang, M.; Xu, Y.; Wang, J.; Liu, M.; Yuan, Z.; Chen, K.; Li, L.; Prud'Homme, R.K.; Guo, X. Biocompatible Nanoparticle based on Dextran-b-Poly(L-Lactide) Block Copolymer formed by Flash Nanoprecipitation. Chem. Lett. 2015, 44, 1688-1690. [CrossRef]

31. Daab, M.; Rosenfeldt, S.; Kalo, H.; Stöter, M.; Bojer, B.; Siegel, R.; Förster, S.; Senker, J.; Breu, J. Two-Step Delamination of Highly Charged, Vermiculite-like Layered Silicates via Ordered Heterostructures. Langmuir 2017, 33, 4816-4822. [CrossRef] [PubMed]

32. Xiong, X.; Cai, Z.; Zhou, D.; Zhang, G.; Zhang, Q.; Jia, Y.; Duan, X.; Xie, Q.; Lai, S.; Xie, T.; et al. A highly-efficient oxygen evolution electrode based on defective nickel-iron layered double hydroxide. Sci. Chin. Mater. 2018, 7, 939-947. [CrossRef]

33. Mu, W.; Zhu, J.; Zhang, S.; Guo, Y.; Su, L.; Li, X.; Li, Z. Novel proposition on mechanism aspects over Fe-Mn/ZSM-5 catalyst for NH3-SCR of NOx at low temperature: Rate and direction of multifunctional electron-transfer-bridge and in-situ DRIFTs analysis. Catal. Sci. Technol. 2016, 6, 7532-7548. [CrossRef]

34. Stahl, A.; Wang, Z.; Schwämmle, T.; Ke, J.; Li, X. Novel Fe-W-Ce Mixed Oxide for the Selective Catalytic Reduction of $\mathrm{NO}_{x}$ with $\mathrm{NH}_{3}$ at Low Temperatures. Catalysts 2017, 7, 71. [CrossRef]

35. Bao, J.; Zhang, X.; Fan, B.; Zhang, J.; Zhou, M.; Yang, W.; Hu, X.; Wang, H.; Pan, B.; Xie, Y. Ultrathin Spinel-Structured Nanosheets Rich in Oxygen Deficiencies for Enhanced Electrocatalytic Water Oxidation. Angew. Chem. 2015, 127, 7507-7512. [CrossRef]

36. Gao, F.; Tang, X.; Yi, H.; Li, J.; Zhao, S.; Wang, J.; Chu, C.; Li, C. Promotional mechanisms of activity and $\mathrm{SO}_{2}$ tolerance of $\mathrm{Co}$ - or Ni-doped $\mathrm{MnO}_{\mathrm{x}}-\mathrm{CeO}_{2}$ catalysts for SCR of $\mathrm{NO}_{\mathrm{x}}$ with $\mathrm{NH}_{3}$ at low temperature. Chem. Eng. J. 2017, 317, 20-31. [CrossRef]

37. Xu, L.; Jiang, Q.; Xiao, Z.; Li, X.; Huo, J.; Wang, S.; Dai, L. Plasma-Engraved $\mathrm{Co}_{3} \mathrm{O}_{4}$ Nanosheets with Oxygen Vacancies and High Surface Area for the Oxygen Evolution Reaction. Angew. Chem. Int. Ed. Engl. 2016, 128, 5363-5367. [CrossRef]

38. Wang, F.; Li, W.-Z.; Lin, J.-D.; Chen, Z.-Q.; Wang, Y. Crucial support effect on the durability of Pt $/ \mathrm{MgAl}_{2} \mathrm{O}_{4}$ for partial oxidation of methane to syngas. Appl. Catal. B Environ. 2018, 231, 292-298. [CrossRef]

39. Gil, A.; Arrieta, E.; Vicente, M.A.; Korili, S.A. Synthesis and $\mathrm{CO}_{2}$ adsorption properties of hydrotalcite-like compounds prepared from aluminum saline slag wastes. Chem. Eng. J. 2018, 334, 1341-1350. [CrossRef] 
40. Wang, C.; Zhai, P.; Zhang, Z.; Zhou, Y.; Zhang, J.; Zhang, H.; Shi, Z.; Han, R.P.S.; Huang, F.; Ma, D. Nickel catalyst stabilization via graphene encapsulation for enhanced methanation reaction. J. Catal. 2016, 334, 42-51. [CrossRef]

41. Yang, J.; Guo, Y. Nanostructured perovskite oxides as promising substitutes of noble metals catalysts for catalytic combustion of methane. Chin. Chem. Lett. 2018, 29, 252-260. [CrossRef] 